OPEN ACCESS

Edited by:

Carsten Watzl,

Leibniz-Institut für Arbeitsforschung an der TU Dortmund (IfADo), Germany

Reviewed by:

Quirin Hammer,

Karolinska Institutet (KI), Sweden

Frank M. Cichocki,

University of Minnesota Twin Cities,

United States

*Correspondence:

Alexander Rölle

a.roelle@dkfz-heidelberg.de

Specialty section:

This article was submitted to

NK and Innate Lymphoid Cell Biology,

a section of the journal

Frontiers in Immunology

Received: 18 August 2018 Accepted: 28 September 2018

Published: 17 October 2018

Citation:

Rölle A, Jäger D and Momburg F (2018) HLA-E Peptide Repertoire and

Dimorphism-Centerpieces in the

Adaptive NK Cell Puzzle?

Front. Immunol. 9:2410

doi: 10.3389/fimmu.2018.02410

\section{HLA-E Peptide Repertoire and Dimorphism-Centerpieces in the Adaptive NK Cell Puzzle?}

\author{
Alexander Rölle ${ }^{1,2 \star}$, Dirk Jäger ${ }^{1,2}$ and Frank Momburg ${ }^{3}$ \\ ${ }^{1}$ Department of Medical Oncology, National Center for Tumor Diseases, University Hospital Heidelberg, Heidelberg, Germany, \\ ${ }^{2}$ Clinical Cooperation Unit Applied Tumor Immunity (D120), German Cancer Research Center, Heidelberg, Germany, ${ }^{3}$ Antigen \\ Presentation and T/NK Cell Activation Group (D121), German Cancer Research Center (DKFZ), Heidelberg, Germany
}

Adaptive Natural Killer (NK) cells, a heterogenous subpopulation of human NK cells with a unique phenotypic and functional signature, became arguably one of the central areas of interest in the field. While their existence seems closely associated with prior exposure to human cytomegalovirus (HCMV), many questions regarding their origin and regulation remain unanswered. However, a common denominator for the majority of adaptive NK cells is the expression of the activating heterodimeric receptor CD94/NKG2C that binds to HLA-E, a non-classical HLA molecule, that displays a comparably restricted expression pattern, very limited polymorphism and presents a distinct set of peptides. Recent studies suggest that -in analogy to $T$ cell responses-peptides presented on HLA-E could play an unexpectedly decisive role for the biology of adaptive NK cells. Here, we discuss how this perspective on the CD94/NKG2C-HLA-E axis aligns with the existing literature and speculate about possible translational implication.

Keywords: adaptive NK cells, NKG2C, HLA-E, HLA-G, leader peptide, Fc\&R $\gamma$

The view of Natural Killer (NK) cells as exclusively innate lymphocytes has been challenged for more than a decade now. Ever since the seminal reports by Gumá et al. $(1,2)$, an increasingly clear picture of human NK cell subsets with adaptive features is emerging. Adaptive NK cells are characterized by a distinct epigenetic signature, alterations in key transcription factors, signaling adaptors, and cell surface receptors (3-6). This phenotype is accompanied by expansions of adaptive NK cell subsets resembling clonal $\mathrm{T}$ cell responses and a functional specialization that seems to favor antibody-triggered responses over natural cytotoxicity (7-9). These features are observed in different combinations on the single cell level, resulting in substantial heterogeneity within the adaptive NK cell subset. While we are far from understanding the biological relevance of this complex picture, two hallmarks-already defined in the early studies by López-Botet's group $(2,10)$-remain unifying features: (1) The majority of adaptive NK cells expresses the activating heterodimeric lectin-like receptor CD94/NKG2C that binds the non-classical HLA-E molecule. (2) Prior exposure to human cytomegalovirus (HCMV) usually seems to precede the emergence of adaptive NK cells, even though adaptive NK subsets have been described in NKG2C-deficient individuals as well where CD2 engagement can compensate for the lack of NKG2C-mediated co-stimulation of antibody-driven responses (11). Other viral infections have been described to trigger the expansion of adaptive subsets, but it seems that this expansion does not take place in CMV-seronegative donors $(10,12,13)$. Since primary CMV infection is usually asymptomatic, most reports are likely studying secondary expansions that accompany CMV reactivation events, 
e.g., after transplantations (14-16). The molecular events underlying the initial formation of the adaptive NK cell subset remain strikingly enigmatic.

Very recently, Hammer et al. (17) as well as our own group (18) highlighted the critical importance of peptides, most notably a peptide derived from the leader sequence of HLA-G, presented on HLA-E for the regulation of adaptive NK cells, further emphasizing the role of this receptor-ligand system. We speculate here that the remarkable degree of peptide specificity together with certain features of the HLA-E biology make a compelling case for the HLA-E/NKG2C axis as the central driver for CMVinduced generation of adaptive NK cells.

We will set out by recapitulating some evolutionary aspects of HLA-E molecules that need to be considered with regard to the ongoing battle between the mammalian immune system and persistently infecting viruses, which holds in particular for the beta-herpes virus CMV that has developed a multitude of immune escape strategies targeting innate as well as adaptive immune responses.

The non-classical MHC class I molecule HLA-E plays a threefold role in the regulation of certain aspects of the innate and adaptive immune system. Firstly, HLA-E molecules loaded with peptides derived from various HLA class I ER leader sequences block conventional NK cells expressing the inhibitory heterodimeric NKG2A/CD94 receptor containing two ITIM motifs in the cytoplasmic domain of NKG2A (19-25). Secondly, HLA-E molecules preferentially loaded with the HLA-G leader peptide have the capacity to trigger ADCC-competent "adaptive" NK cells expressing the activating NKG2C/CD94 receptor that is associated with the ITAM-containing adaptor molecule DAP12 $(17,18,22,26,27)$. Thirdly, HLA-E molecules presenting various self and virus-derived peptides can be ligands for $\mathrm{CD}^{+}$ cytotoxic T cells expressing $\alpha \beta$ T cell receptors (28-33). HLA-Erestricted $\mathrm{T}$ cell responses are, however, beyond the focus of this Perspective.

\section{UNIQUE EVOLUTIONARY FEATURES OF DIMORPHIC HLA-E MOLECULES}

Evolutionary studies indicate that the HLA-E locus is the most well conserved among all primate MHC major histocompatibility complex (MHC) class I genes (34) indicating that it serves specialized functions in the immune system distinct from the highly polymorphic HLA-A, B, and C locus products. In humans two allelic variants can be distinguished in Caucasian populations that differ only in amino acid 107 (Arg in HLA-E*0101, Gly in HLA-E*01031 and $\left.E^{*} 01032\right)(35,36)$. Amino acid 107 is located in an outwardly exposed loop below the $\alpha_{2}$-helix of the peptide-binding platform and does not affect the general structure of peptide-assembled HLA-E molecules (37). While HLA-E ${ }^{G}$ seems to be older allele since Gly107 is exclusively found in all primate HLA-E orthologs, population studies suggest that the HLA-E $\mathrm{E}^{\mathrm{R}}$ single nucleotide polymorphism has emerged before the expansion of Homo sapiens (38). HLA-E $\mathrm{E}^{\mathrm{G}}$ and HLA-E $\mathrm{E}^{\mathrm{R}}$ alleles occur in about equal frequencies in different ethnic groups and are maintained in diverse ancestral HLA haplotypes by stabilizing selection (38). While influences of the genetic HLA-E dimorphism on graft-vs.-leukemia reactions after hematopoietic stem cell transplantation, spontaneous abortions, viral infections, and susceptibility to autoimmune diseases have been described elsewhere (39-42), we will focus here on features of HLA-E proteins related to the formation of ligands for CD94/NKG2A/C NK receptors.

\section{PEPTIDE-LOADED HLA-E MOLECULES AS BINDING PARTNERS FOR NKG2A/C}

While HLA-E transcripts show a broad tissue distribution (43), surface expression of of HLA-E proteins is mainly restricted to resting and activated T cells, NK cells, B cells, monocytes, and macrophages as well as endothelial cells $(23,44)$. Hence NKG2A-expressing NK cells that circulate through blood vessels and lymphoid tissues will constantly be exposed to varying levels of inhibitory stimuli. Due to the $\sim 6$-fold lower affinity of peptide-loaded HLA-E molecules to NKG2C $(45,46)$ and stricter peptide selectivity of the HLA-E/NKG2C interaction $(17,18,22,47)$ it seems, however, more unlikely that $\mathrm{NKG}_{2} \mathrm{C}^{+}$ NK cells will receive tonic stimulation under physiological conditions. While HLA-E was noted to possess generally low surface expression levels as compared with HLA-A and B molecules, the HLA-E ${ }^{G}$ allotype loaded with different peptides shows consistently higher surface expression than HLA-E ${ }^{\mathrm{R}}$ (37, $48,49)$. This can be attributed to various factors including less efficient assembly with $\beta_{2}$-microglobulin and slower ER egress, lower affinity for all tested HLA leader peptide ligands and reduced thermostability of the $\operatorname{HLA}-\mathrm{E}^{\mathrm{R}}$ variant $(37,48,49)$. This suggests that background NKG2A/C engagement will be very low in the HLA-E $\mathrm{E}^{\mathrm{R}}$ homozygous situation which might reduce the inhibition/activation threshold of $\mathrm{NKG}_{2} \mathrm{~A}^{+} / \mathrm{C}^{+} \mathrm{NK}$ cells, but also of $\mathrm{NKG}_{2} \mathrm{~A}^{+} \mathrm{T}$ cells, during viral infection and other pathological conditions (50). In this context it is interesting to note that the presence of the HLA-E ${ }^{G}$ variant was reported to be associated with higher incidence of CMV infection after kidney transplantation (51), which might be related to a more pronounced dampening of $\mathrm{NKG}_{2} \mathrm{~A}^{+} \mathrm{NK}$ cell responses.

The HLA-E ligands for NKG2 family members are usually formed after loading HLA-E molecules with 9-mer peptides processed out of ER leader sequences from various HLA-A, B, and $\mathrm{C}$ allotypes as well as HLA-G in a TAP- and proteasomedependent fashion $(22,24,25,52-54)$. HLA-E-stabilizing leader peptides that confer protection from NK cell lysis by binding to NKG2A have the consensus sequence VM(A/P)PRT(L/V) (V/L/I/F)L and thus exclude several HLA-B allotypes (containing a Thr or Ala residue instead of Met), a few HLA-C allotypes and the leader peptides from HLA-F and HLA-E itself that do not match this motif. HLA-E molecules thereby monitor the biosynthesis of most polymorphic class I allotypes as well as the class Ib molecule HLA-G and regulates NK cell activity as a functional complement to the polymorphic KIR system.

During cellular stress Hsp60 is upregulated and can give rise to a competing HLA-E ligand (55). HLA-E/Hsp60 leader peptide 
complexes are not bound by NKG2A/CD94 and thus provide a mechanism for NK cells to specifically attack stressed cells (55). In addition to the Hsp60 peptide, a great number of noncanonical, sometimes pathogen-derived HLA-E ligands (with striking differences between HLA-E $\mathrm{E}^{\mathrm{G}}$ and HLA-E $\mathrm{E}^{\mathrm{R}}$ ) have been identified (56-59) that will probably be of little relevance for NK cell recognition.

By clear contrast, the requirements for the recognition of peptide-loaded HLA-E molecules by NKG2C/CD94 are much more restricted. It was noted that the HLA-G-derived leader peptide VMAPRTLFL in complex with HLA-E has a dominant role in inducing cytotoxic activity in $\mathrm{NKG}_{2} \mathrm{C}^{+} \mathrm{NK}$ cell clones using peptide-pulsed, HLA-E* 0101 -expressing 721.221 Blymphoblastoid cells or PBMC as stimulators $(22,47)$. Using microspheres charged with recombinant peptide-loaded HLA$E^{*} 0103$ molecules we have recently shown that only the HLA$\mathrm{E}^{\mathrm{pHLA}-\mathrm{G}}$ complex is able to trigger FceRI $\gamma$ downmodulation, IFN- $\gamma$ release, CD25 upregulation, proliferation, and ADCC responses in $\mathrm{NKG}_{2} \mathrm{C}^{+} \mathrm{NK}$ cells (18). The pivotal role of the HLA$\mathrm{G}$ peptide for NKG2C/CD94 stimulation in vitro appears to be in accordance with biochemical studies analyzing the affinities and thermodynamic parameters of NKG2x/CD94-pHLA-E interactions (46). Crystal structures surprisingly revealed that the critical Phe ${ }_{8}$ residue in the HLA-G peptide is in contact with CD94 but not with the differentially regulated NKG2A/C chains $(60,61)$. The predominance of the HLA-G peptide-loaded HLA$\mathrm{E}$ for adaptive NK cells prompts questions regarding the natural availability of such complexes in light of the restricted tissue distribution of HLA-G (62-64).

\section{HUMAN CYTOMEGALOVIRUS (CMV) INFLUENCES THE HLA-E/NKG2 INTERACTION}

Human cytomegalovirus has highjacked the HLA-E/NKG2A axis for the purpose of immune evasion. In the presence of TAP peptide transporter blockade through the CMV protein US6, HLA signal peptide-mimicking sequences derived from the CMV glycoprotein UL40 are able to supply HLA-E molecules with stabilizing peptides TAP-independently $(65,66)$. Interestingly, the early HCMV gene products US2 and US11, that attack HLA$\mathrm{A}, \mathrm{B}, \mathrm{C}$, and $\mathrm{G}$ molecules in an allotype-specific fashion, do not downmodulate HLA-E heavy chains (67); and the HLA- $\mathrm{E}^{\mathrm{G}}$ but not the HLA- $\mathrm{E}^{\mathrm{R}}$ alloform may be resistant to TAP blockade by US6 $(67,68)$. The HCMV glycoprotein US10 selectively targets the NK-inhibitory HLA-G molecule for degradation while HLA-E levels are only slightly affected (69). Since HLA$\mathrm{G}$ is inserted into the ER membrane before US10-mediated degradation, HLA-G leader peptides will likely remain available for HLA-E loading and NKG2C interaction in CMV-infected tissues unless their ER entry is blocked by the late HCMV gene product US6. We conclude that HLA-E appears to be remarkably spared from the attack of HCMV immunoevasins principally favoring not only the blockade of conventional NKG2A ${ }^{+}$ NK cells but simultaneously also the expansion of $\mathrm{NKG}^{+} \mathrm{C}^{+}$ NK cells.

\section{ADAPTIVE NK CELLS BENEFIT FROM HLA-E LOADED WITH CMV UL40-DERIVED PEPTIDES}

There seems to be an ongoing coevolution likely resulting in mutual benefit for the propagation of HCMV variants and the persistently infected human host. This assumption is underpinned by the finding that in clinical HCMV isolates, the UL40 protein shows a mutational hotspot at position 8 of the potential HLA-E-binding peptide at position UL40(15-24) (70). Some UL40 variant peptides reduced the affinity of the interaction between HLA-E and CD94/NKG2A and some selectively reduced the $\mathrm{NK}$ cell-mediated lysis by $\mathrm{NKG}_{2} \mathrm{C}^{+} \mathrm{NK}$ cell clones (70). Notably, UL40 is endowed with a dual function and does not only provide HLA-E binding sequences but also promotes UL18 expression (71). The UL18 gene product is a high affinity decoy-ligand for the inhibitory receptor LIR-1 (72), that is highly expressed on adaptive NK cells and that mediates decreased susceptibility of HCMV-infected cells to LIR$1^{+}$NK cells (73). This could suggest that the immune-evasive functions of UL40 are primarily targeted at adaptive NK cell populations. In a very profound analysis it was recently shown that UL40-encoded peptides control the activation, expansion and differentiation of $\mathrm{NKG}_{2} \mathrm{C}^{+}$adaptive $\mathrm{NK}$ cells in a subtle fashion (17). A rare UL40 peptide identical with the abovementioned HLA-G leader peptide was confirmed to be optimally stimulating, followed by a frequent UL40-derived peptide mimicking the leader peptide present in most HLA-C alleles (VMAPRTLIL) (17). This study elegantly recapitulated prior knowledge regarding the epigenetic imprinting and expansion of adaptive $\mathrm{NKG}_{2} \mathrm{C}^{+} \mathrm{NK}$ cells in the presence of genetically diverse HCMV strains. The authors propose that different strain-specific UL40-derived peptides account for the heterogeneity of adaptive NK cell populations.

\section{HCMV-DRIVEN PRIMING AND EXPANSION OF ADAPTIVE NK CELLS}

The relevance of HLA-E-NKG2C interactions for the expansion of adaptive NK cells has been demonstrated in vitro $(2,74-$ 76) and is supported by studies showing that NKG2C zygosity directly correlates with NKG2C surface levels and the size and distribution of $\mathrm{NKG}_{2} \mathrm{C}^{+} \mathrm{NK}$ cells in vivo (77-79).

Interestingly, Gumá et al. had already studied the influence of HLA-E alleles-and thereby presumably HLA-E surface levelson HCMV serology and percentage of $\mathrm{NKG}_{2} \mathrm{C}^{+}$cells. While the limited number of subjects makes definitive conclusions challenging, the authors noted a weaker correlation between NKG2C expression and HCMV serology in individuals with the HLA-E ${ }^{G}$ allele, i.e., potentially higher HLA-E expression (1). Does this indicate a more successful antiviral NK cell response via NKG2C-HLA-E ${ }^{G}$ which is in turn reflected by reduced antibody responses? Or is an increased ligand engagement of NKG2C, both under homeostatic conditions as well as during HCMV infection, an underlying reason for the lower percentage of cells with the NKG2C receptor in HLA-E $\mathrm{E}^{\mathrm{G}}$ homozygous individuals? 


\section{A Primary HCMV infection}

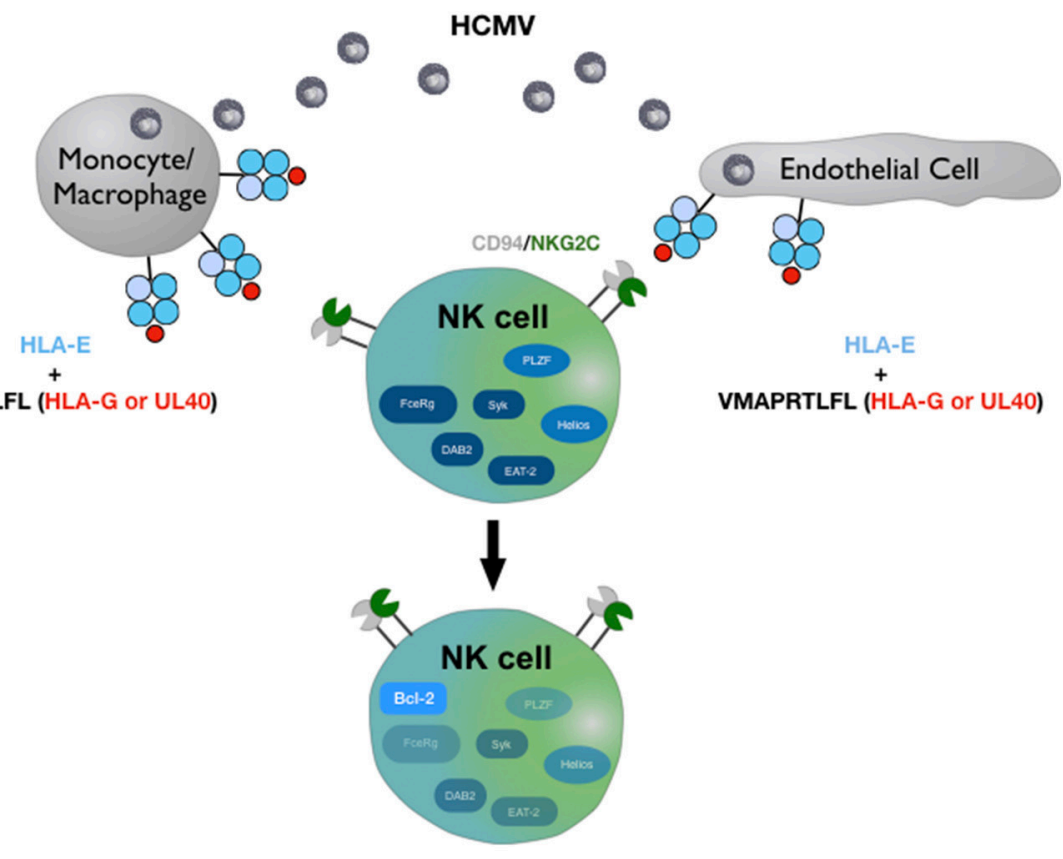

\section{B HCMV reactivation or other infections}

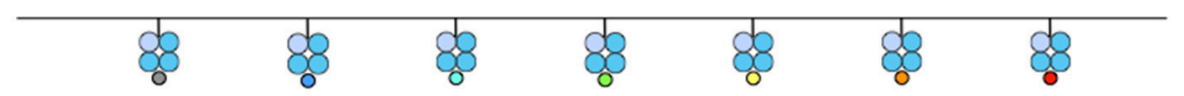

Adaptive NK cell heterogeneity as a result of interaction with different HLA-E-peptide ligands
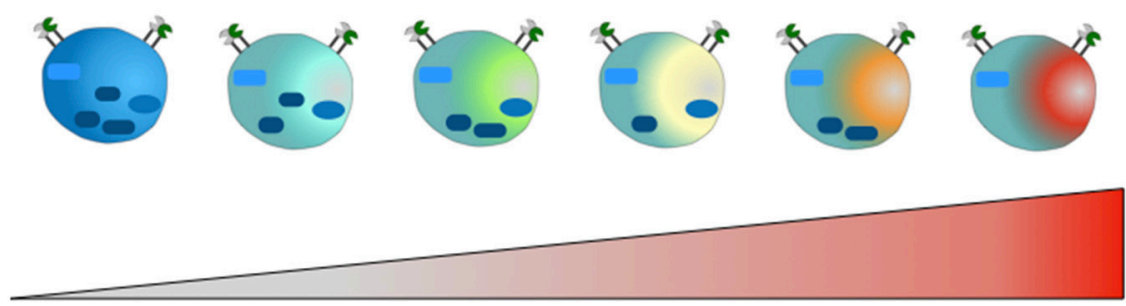

Strength of CD94/NKG2C-HLA-E Interactions

FIGURE 1 | Hypothetical model of adaptive NK cell differentiation driven by the HLA-E ligandome. (A) Monocytes/macrophages and endothelial cells represent the primary site of CMV infection and consecutive latency. Simultaneous expression of HLA-E and increased availability of HLA-G-derived peptides - either derived from rare viral UL40 variants or from cellular HLA-G, upregulated during infection-generate HLA-E molecules in complex with the HLA-G-derived peptide VMAPRTLFL.

This strong ligand triggers adaptive NK cells (or precursors) via the heterodimeric CD94-NKG2C receptor, which initiates epigenetic imprinting and the gradual loss of signaling molecules, e.g., Fc\&Ry or transcription factors, e.g., PLZF. (B) Reactivation of CMV from latency reservoirs or other infections that affect HLA-E levels and/or the pool of presented peptides provide a diverse range of ligands for CD94-NKG2C. Depending on the respective affinities and the ensuing interactions, adaptive NK cells continue to downregulate additional molecules of intracellular signaling, eventually giving rise to an increasingly heterogenous population of adaptive NK cells. For reasons of clarity, the figure does not take into account that different HLA-E alleles result in different HLA-E expression levels and that infections are accompanied by distinct cytokine signatures. We also omit the characteristic modulation of cell surface receptors on adaptive NK cells compared to canonical NK cells and the potential need for costimulation for weak HLA-E-peptide ligands.

An intriguing open question remains why HCMV appears to have such a decisive role for the generation and expansion of adaptive NK cell populations (80). What is the difference compared to other pathogens, and which combination of parameters is unique to cytomegalovirus? Together with recent studies, that show the profound impact of the HLA-G-derived 
leader peptide $(17,18)$, we are tempted to speculate that only CMV infection provides both, elevated HLA-E and HLA-G expression on a single cell level. Interestingly, a polymorphism in the $3^{\prime}$-untranslated region of the HLA-G gene that affects HLA$\mathrm{G}$ expression levels has been reported to modify susceptibility to CMV infection (81). Macrophages and monocytes express HLA-E $(23,44)$ and de novo induction of monocyte HLA-G cell surface expression was reported for active HCMV infection (77) and reactivation of latent infection in vitro (82). HLA$\mathrm{G}$ upregulation in monocytes/macrophages is supported by increased levels of cellular IL-10 and cmvIL-10 (HCMV gene product UL111A) during infection while expression of classical MHC class I molecules is suppressed $(83,84)$. Intriguingly, monocytes, monocyte-derived macrophages, and DCs were identified as the major cellular target for cmvIL-10 and hIL10 (85). Co-expression of HCMV gene products and HLA-G has been demonstrated for macrophages with reactivated CMV infection on a single-cell level (82). In line with studies using cell lines overexpressing CMV immunoevasins US2, US3, or US6 $(86,87)$, other researchers noted, however, a down-regulation of HLA-G cell surface expression in freshly CMV-infected astrocytoma cells in vitro (88). For a successful loading of HLA-E molecules with HLA-G leader peptide the activity of the TAPblocking HCMV immunoevasin US6 is, in our opinion, of foremost relevance. US6 expression levels peak only around $48 \mathrm{~h}$ post-infection and then slowly decrease (89). Since US2 and US11, showing maximum expression levels within $24 \mathrm{~h}$ postinfection (89), do not affect HLA-E surface expression (67) we propose that there is a sufficient time window for the formation of HLA- $\mathrm{E}^{\mathrm{pHLA}-\mathrm{G}}$ complexes in a subset of acutely CMV-infected monocytes/macrophages before TAP inhibition through US6 sets in and HLA-E continues to be supplied with UL40-derived TAPindependent peptide ligands. The study by Onno et al. (82) indicates that even 20 days after reactivation of latent CMV high HLA-G levels can be observed in infected macrophages while only a partial down-modulation of HLA-A,B,C molecules was noted, suggesting that the activity of US6 may have ceased. In this setting, which may aptly reflect the in vivo situation of a chronic CMV infection with sporadic reactivations, HLA$\mathrm{E}^{\mathrm{pHLA}-\mathrm{G}}$ complexes should be abundant.

A similar setting seems possible for endothelial cells that were reported to trigger $\mathrm{NKG}_{2} \mathrm{C}^{+} \mathrm{NK}$ cells upon primary CMV infection (90) and that represent a major non-lymphoid cell type displaying substantial HLA-E expression, particularly under inflammatory conditions (44). This would permit a scenario of sufficient HLA-E complexes, presenting the VMAPRTLFL peptide. Since both, monocytes as well as endothelial cells are considered reservoirs of viral latency (91), they could also act as critical mediators for secondary expansion of adaptive NK cells upon CMV reactivation which aligns with in vitro data $(6,75$, 90) and a study that observed a correlation between monocyte counts and the magnitude of $\mathrm{NKG}_{2} \mathrm{C}^{+} \mathrm{NK}$ cell expansion during reactivation (92).

If we consider the differential reactivity of NKG2C with HLAE-bound leader peptides together with the allelic dimorphism of HLA-E itself, it becomes clear that one has to envisage a range of NKG2C ligands with different affinities expressed at different surface densities. Weaker NKG2C ligands were shown to require costimulation through $\mathrm{CD} 2$ for adaptive NK cell triggering through CD16 and to have a lesser impact on gene methylation (17). The VMAPRTLFL peptide is set apart from other HLA-E ligands by its strong impact on adaptive NK cell populations. Whether it is primarily derived from rare UL40 variants as described by Hammer et al. (17) or more often the result of increased cellular HLA-G levels as a consequence of HCMV infection remains an open question.

In light of the exquisite peptide specificity of adaptive NK cells, we hypothesize that the strength of the HLAE/NKG2C interaction in conjunction with variable conditions of costimulation and a favorable cytokine milieu is the molecular basis for the complex inter- and intraindividual heterogeneity of adaptive NK cells (Figure 1). To test this hypothesis, future studies have to systematically dissect the impact of different HLAE-peptide ligands on the characteristic epigenetic profile and altered intracellular signaling of adaptive NK cells.

\section{ADAPTIVE NK CELLS IN CELLULAR IMMUNOTHERAPY-A VIABLE OPTION FOR HLA-E ${ }^{+}$TUMORS?}

Mounting evidence indicates that CMV reactivation can result in a reduced relapse rate in acute myelogenous leukemia $(93,94)$ and chronic myelogenous leukemia (95). Cichocki et al. observed that patients with hematologic malignancies receiving HSCT displayed a selective and sustained expansion of adaptive NK cells after experiencing CMV reactivation (92), and another report showed higher cytotoxicity of adaptive NK cells from CMVseropositive donors compared to seronegative donors (96). This suggests that adaptive NK cell subsets can mediate a substantial anti-leukemia effect, even though the molecular mechanisms remain unclear at this point. A recent study demonstrated that the reactivity against primary pediatric ALL blasts is largely independent of CD94(/NKG2C)-HLA-E interactions but rather relies on "missing-self" recognition (97) and possibly DNAM-1 (98). However, NK cell activation and receptor usage can vary dramatically depending on the cellular context and the therapeutic potential of adaptive NK cells, particularly in tumor entities that are characterized by increased HLA-E levels, merits further investigation. High expression of non-classical MHC class I molecules is often associated with poor clinical prognosis $(62,64,99)$, rendering those malignancies a potential scenario for the utilization of $\mathrm{NKG}_{2} \mathrm{C}^{+} \mathrm{NK}$ cells. Cellular immunotherapies might also benefit from other favorable properties, e.g., elevated resistance to MDSC and $\mathrm{T}_{\text {reg }}$ suppression, that were ascribed to adaptive NK cell populations $(100,101)$. Given their superior capacity for mediating ADCC, adaptive NK cells could also be combined with therapeutic interventions relying on monoclonal antibodies, bi-specific or tri-specific killer engagers (BiKEs/TriKEs) (102).

First steps toward devising clinical protocols for the use of adaptive NK cells have been taken and promise cellular NK cell-based therapies with higher efficiency (97). Expansion of $\mathrm{NKG}_{2} \mathrm{C}^{+}$cells by HLA-E expressing transfectants is a successful 
strategy for obtaining robust proliferation $(74,97)$ of functional adaptive NK cell populations. In light of recent findings regarding the remarkable peptide specificity of adaptive NK cells $(17,18$, 47) a further optimization of these approaches by tailoring the peptide ligand on HLA-E appears desirable.

\section{REFERENCES}

1. Gumá M, Angulo A, Vilches C, Gómez-lozano N, Malats N, López-Botet M. Imprint of human cytomegalovirus infection on the NK cell receptor repertoire. Blood (2004) 104:3664-71. doi: 10.1182/blood-2004-05-2058

2. Gumá M, Budt M, Sáez A, Brckalo T, Hengel H, Angulo A, et al. Expansion of CD94/NKG2C ${ }^{+} \mathrm{NK}$ cells in response to human cytomegalovirus-infected fibroblasts. Blood (2006) 107:3624-31. doi: 10.1182/blood-2005-09-3682

3. Hwang I, Zhang T, Scott JM, Kim AR, Lee T, Kakarla T, et al. Identification of human NK cells that are deficient for signaling adaptor $\mathrm{FcR} \gamma$ and specialized for antibody-dependent immune functions. Int Immunol. (2012) 24:793802. doi: 10.1093/intimm/dxs080

4. Béziat V, Liu L, Malmberg JA, Ivarsson MA, Sohlberg E, Björklund AT, et al. NK cell responses to cytomegalovirus infection lead to stable imprints in the human KIR repertoire and involve activating KIRs. Blood (2013) 121:2678-88. doi: 10.1182/blood-2012-10-459545

5. Lee J, Zhang T, Hwang I, Kim A, Nitschke L, Kim M, et al. Epigenetic modification and antibody-dependent expansion of memory-like NK Cells in human cytomegalovirus-infected individuals. Immunity (2015) 42:43142. doi: 10.1016/j.immuni.2015.02.013

6. Schlums H, Cichocki F, Tesi B, Theorell J, Beziat V, Holmes TD, et al. Cytomegalovirus infection drives adaptive epigenetic diversification of $\mathrm{NK}$ Cells with altered signaling and effector function. Immunity (2015) 42:44356. doi: 10.1016/j.immuni.2015.02.008

7. Lopez-Verges S, Milush JM, Schwartz BS, Pando MJ, Jarjoura J, York VA, et al. Expansion of a unique $\mathrm{CD} 57^{+} \mathrm{NKG} 2 \mathrm{C}^{\text {hi }}$ natural killer cell subset during acute human cytomegalovirus infection. Proc Natl Acad Sci USA. (2011) 108:14725-32. doi: 10.1073/pnas.1110900108

8. Zhang T, Scott J, Hwang I, Kim S. Cutting Edge: antibody-dependent memory-like NK cells distinguished by FcR $\gamma$ deficiency. J Immunol. (2013) 190:1402-6. doi: 10.4049/jimmunol.1203034

9. Wu Z, Sinzger C, Frascaroli G, Reichel J, Bayer C, Wang L, et al. Human Cytomegalovirus-induced NKG2C ${ }^{\text {hi }}$ CD57 ${ }^{\text {hi }}$ natural killer cells are effectors dependent on humoral antiviral immunity. J Virol. (2013) 87:7717-25. doi: 10.1128/JVI.01096-13

10. Gumá M, Cabrera C, Erkizia I, Bofill M, Clotet B, Ruiz L, et al. Human Cytomegalovirus infection is associated with increased proportions of $\mathrm{NK}$ cells that express the CD94/NKG2C receptor in aviremic HIV-1-positive patients. J Infect Dis. (2006) 194:38-41. doi: 10.1086/504719

11. Liu LL, Landskron J, Ask EH, Enqvist M, Sohlberg E, Traherne JA, et al. Critical role of CD2 co-stimulation in adaptive $\mathrm{NK}$ cell responses revealed in NKG2C-deficient humans. Cell Rep. (2016) 15:1-12. doi: 10.1016/j.celrep.2016.04.005

12. Björkström NK, Riese P, Heuts F, Andersson S, Fauriat C, Ivarsson MA, et al. Expression patterns of NKG2A, KIR, and CD57 define a process of CD56 dim NK-cell differentiation uncoupled from NK-cell education. Blood (2010) 116:3853-64. doi: 10.1182/blood-2010-04-281675

13. Béziat V, Dalgard O, Asselah T, Halfon P, Bedossa P, Boudifa A, et al. CMV drives clonal expansion of $\mathrm{NKG}_{2} \mathrm{C}^{+} \mathrm{NK}$ cells expressing self-specific KIRs in chronic hepatitis patients. Eur J Immunol. (2012) 42:447-57. doi: 10.1002/eji.201141826

14. Foley B, Cooley S, Verneris MR, Curtsinger J, Luo X, Waller EK, et al. Human cytomegalovirus (CMV)-induced memory-like $\mathrm{NKG}_{2} \mathrm{C}^{+} \mathrm{NK}$ cells are transplantable and expand in vivo in response to recipient $\mathrm{CMV}$ antigen. J Immunol. (2012) 189:5082-8. doi: 10.4049/jimmunol.1201964

15. Foley B, Cooley S, Verneris MR, Pitt M, Curtsinger J, Luo X, et al. Cytomegalovirus reactivation after allogeneic transplantation promotes a lasting increase in educated $\mathrm{NKG}_{2} \mathrm{C}^{+}$natural killer cells with potent function. Blood (2011) 2665-74. doi: 10.1182/blood-2011-10-386995

\section{AUTHOR CONTRIBUTIONS}

AR defined the scope, wrote the manuscript, and generated the figure. DJ discussed the underlying concepts. FM discussed the underlying concepts and wrote the manuscript.

16. Della Chiesa M, Falco M, Bertaina A, Muccio L, Alicata C, Frassoni F, et al. Human Cytomegalovirus infection promotes rapid maturation of NK cells expressing activating killer Ig-like receptor in patients transplanted with NKG2C ${ }^{-/-}$umbilical cord blood. J Immunol. (2014) 192:1471-9. doi: 10.4049/jimmunol.1302053

17. Hammer Q, Rückert T, Borst EM, Dunst J, Haubner A, Durek P, et al. Peptide-specific recognition of human cytomegalovirus strains controls adaptive natural killer cells article. Nat Immunol. (2018) 19:453-63. doi: 10.1038/s41590-018-0082-6

18. Rölle A, Meyer M, Calderazzo S, Jäger D, Momburg F. Distinct HLA-E peptide complexes modify antibody-driven effector functions of adaptive NK cells. Cell Rep. (2018) 24:1967-76.e4. doi: 10.1016/j.celrep.2018.07.069

19. Lazetic S, Chang C, Houchins JP, Lanier LL, Phillips JH. Human natural killer cell receptors involved in MHC class I recognition are desulfide-linked heterodimers of CD94 and NKG2 subunits. J Immunol. (1996) 157:4741-45.

20. Brooks AG, Posch PE, Scorzelli CJ, Borrego F, Coligan JE. NKG2A Complexed with CD94 defines a novel inhibitory natural killer cell receptor. J Exp Med. (1997) 185:795-800. doi: 10.1084/jem.185.4.795

21. Braud VM, Jones YE, McMichael AJ. The human major histocompatibility complex class Ib molecule HLA-E binds signal sequence-derived peptides with primary anchor residues at positions 2 and 9. Eur J Immunol. (1997) 27:1164-9. doi: 10.1002/eji.1830270517

22. Llano M, Lee N, Navarro F, García P, Albar JP, Geraghty DE, et al. HLA-E-bound peptides influence recognition by inhibitory and triggering CD94/NKG2 receptors: Preferential response to an HLA-G-derived nonamer. Eur J Immunol. (1998) 28:2854-63.

23. Lee N, Goodlett DR, Ishitani A, Marquardt H, Geraghty DE. HLA-E surface expression depends on binding of TAP-dependent peptides derived from certain HLA class I signal sequences. J Immunol. (1998) 160:4951-60.

24. Braud VM, Allan DS, O'Callaghan CA, Söderström K, D’Andrea A, Ogg GS, et al. HLA-E binds to natural killer cell receptors CD94/NKG2A, B and C. Nature (1998) 391:795-99.

25. Borrego F, Ulbrecht M, Weiss EH, Coligan JE, Brooks AG. Recognition of human histocompatibility leukocyte antigen (HLA)-E complexed with HLA class I signal sequence-derived peptides by CD94/NKG2 confers protection from natural killer cell-mediated lysis. J Exp Med. (1998) 187:813-8. doi: 10.1084/jem.187.5.813

26. Houchins JP, Lanier LL, Niemi EC, Phillips JH, Ryan JC. Natural killer cell cytolytic activity is inhibited by NKG2-A and activated by NKG2-C. J Immunol. (1997) 158:3603-9.

27. Lanier LL, Corliss B, Wu J, Phillips JH. Association of DAP12 with activating CD94/NKG2C NK cell receptors. Immunity (1998) 8:693-701. doi: 10.1016/S1074-7613(00)80574-9

28. Pietra G, Romagnani C, Mazzarino P, Falco M, Millo E, Moretta A, et al. HLA-E-restricted recognition of Cytomegalovirus-derived peptides by human CD8 ${ }^{+}$cytolytic T lymphocytes. Proc Natl Acad Sci USA. (2003) 100:10896-901. doi: 10.1073/pnas.1834449100

29. García P, Llano M, De Heredia AB, Willberg CB, Caparrós E, Aparicio P, et al. Human T cell receptor-mediated recognition of HLA-E. Eur J Immunol. (2002) 32:936-44. doi: 10.1002/1521-4141(200204)32:4<936::AIDIMMU936>3.0.CO;2-M

30. Romagnani C, Pietra G, Falco M, Millo E, Mazzarino P, Biassoni R, et al. Identification of HLA-E-specific alloreactive T lymphocytes: a cell subset that undergoes preferential expansion in mixed lymphocyte culture and displays a broad cytolytic activity against allogeneic cells. Proc Natl Acad Sci USA. (2002) 99:11328-33. doi: 10.1073/pnas.172369799

31. Pietra G, Romagnani C, Falco M, Vitale M, Castriconi R, Pende D, et al. The analysis of the natural killer-like activity of human cytolytic $\mathrm{T}$ lymphocytes revealed HLA-E as a novel target for TCR $\alpha / \beta$-mediated 
recognition. Eur J Immunol. (2001) 31:3687-93. doi: 10.1002/15214141(200112)31:12\&\#60;3687::AID-IMMU3687\&\#62;3.0.CO;2-C

32. Allard M, Tonnerre P, Nedellec S, Oger R, Morice A, Guilloux $\mathrm{Y}$, et al. HLA-E-restricted cross-recognition of allogeneic endothelial cells by CMVassociated CD8 T cells: a potential risk factor following transplantation. PLoS ONE (2012) 7:e50951. doi: 10.1371/journal.pone.0050951

33. Jouand N, Bressollette-Bodin C, Gérard N, Giral M, Guérif P, Rodallec A, et al. HCMV triggers frequent and persistent UL40-specific unconventional HLA-E-restricted CD8 T-cell responses with potential autologous and allogeneic peptide recognition. PLoS Pathog. (2018) 14:1-30. doi: 10.1371/journal.ppat.1007041

34. Knapp LA, Cadavid LF, Watkins DI. The MHC-E locus is the most well conserved of all known primate class I histocompatibility genes. J Immunol. (1998) 160:189-96.

35. Grimsley C, Kawasaki A, Gassner C, Sageshima N, Nose Y, Hatake K, et al. Definitive high resolution typing of HLA-E allelic polymorphisms: identifying potential errors in existing allele data. Tissue Antigens (2002) 60:206-12. doi: 10.1034/j.1399-0039.2002.600302.x

36. Geraghty DE, Stockschleader M, Ishitani A, Hansen JA. Polymorphism at the HLA-E locus predates most HLA-A and -B polymorphism. Hum Immunol. (1992) 33:174-84. doi: 10.1016/0198-8859(92)90069-Y

37. Strong RK, Holmes MA, Li P, Braun L, Lee N, Geraghty DE. HLAE allelic variants: correlating differential expression, peptide affinities, crystal structures, and thermal stabilities. J Biol Chem. (2003) 278:5082-90. doi: $10.1074 /$ jbc.M208268200

38. Grimsley C, Ober C. Population genetic studies of HLAE: evidence for selection. Hum Immunol. (1997) 52:33-40. doi: 10.1016/S0198-8859(96)00241-8

39. Hodgkinson A, Millward B, Demaine A. The HLA-E locus is associated with age at onset and susceptibility to type 1 diabetes mellitus. Hum Immunol. (2000) 61:290-5. doi: 10.1016/S0198-8859(99)00116-0

40. Lajoie J, Hargrove J, Zijenah LS, Humphrey JH, Ward BJ, Roger M. Genetic variants in nonclassical major histocompatibility complex class I human leukocyte antigen (HLA)-E and HLA-G molecules are associated with susceptibility to heterosexual acquisition of HIV-1. J Infect Dis. (2006) 193:298-301. doi: 10.1086/498877

41. Tripathi P, Naik S, Agrawal S. HLA-E and immunobiology of pregnancy. Tissue Antigens (2006) 67:207-13. doi: 10.1111/j.1399-0039.2005.00550.x

42. Schulte D, Vogel M, Langhans B, Krämer B, Körner C, Nischalke HD, et al. The HLA- $\mathrm{E}^{\mathrm{R}} / \mathrm{HLA}-\mathrm{E}^{\mathrm{R}}$ genotype affects the natural course of hepatitis $\mathrm{C}$ virus $(\mathrm{HCV})$ infection and is associated with HLA-E-restricted recognition of an HCV-derived peptide by interferon- $\gamma$-secreting human CD8 ${ }^{+}$T Cells. J Infect Dis. (2009) 200:1397-401. doi: 10.1086/605889

43. Wei X, Orr HT. Differential expression of HLA-E, HLA-F and HLAG transcripts in human tissue. Hum Immunol. (1990) 29:131-42. doi: 10.1016/0198-8859(90)90076-2

44. Coupel S, Moreau A, Hamidou M, Horejsi V, Soulillou J. Expression and release of soluble HLA-E is an immunoregulatory feature of endothelial cell activation. Blood (2008) 109:2806-814. doi: 10.1182/blood-2006-06-030213

45. Valés-Gómez M, Reyburn HT, Erskine RA, López-Botet M, Strominger JL. Kinetics and peptide dependency of the binding of the inhibitory NK receptor CD94/NKG2-A and the activating receptor CD94/NKG2-C to HLA-E. EMBO J. (1999) 18:4250-60. doi: 10.1093/emboj/18.15.4250

46. Kaiser BK, Barahmand-pour F, Paulsene W, Medley S, Geraghty DE, Strong RK. Interactions between NKG2x immunoreceptors and HLA-E ligands display overlapping affinities and thermodynamics. I Immunol. (2005) 174:2878-84. doi: 10.4049/jimmunol.174.5.2878

47. Lauterbach N, Wieten L, Popeijus HE, Voorter CE, Tilanus MG. HLAE regulates $\mathrm{NKG}_{2} \mathrm{C}^{+}$natural killer cell function through presentation of a restricted peptide repertoire. Hum Immunol. (2015) 76:578-86. doi: 10.1016/j.humimm.2015.09.003

48. Maier S, Grzeschik M, Weiss EH, Ulbrecht M. Implications of HLA-E allele expression and different HLA-E ligand diversity for the regulation of NK cells. Hum Immunol. (2000) 61:1059-65. doi: 10.1016/S0198-8859(00)00190-7

49. Ulbrecht M, Couturier A, Martinozzi S, Pla M, Srivastava R, Peterson PA, et al. Cell surface expression of HLA-E: interaction with human beta2microglobulin and allelic differences. Eur J Immunol. (1999) 29:537-47.

50. Orr MT, Lanier LL. Natural killer cell education and tolerance. Cell (2010) 142:847-56. doi: 10.1016/j.cell.2010.08.031
51. Guberina H, Da Silva Nardi F, Michita RT, Dolff S, Bienholz A, Heinemann FM, et al. Susceptibility of HLA-E*01:03 allele carriers to develop cytomegalovirus replication after living-donor kidney transplantation. $J$ Infect Dis. (2018) 217:1918-22. doi: 10.1093/infdis/jix638

52. Lee $N$, Llano $M$, Carretero $M$, Ishitani A, Navarro F, López-Botet $\mathrm{M}$, et al. HLA-E is a major ligand for the natural killer inhibitory receptor CD94/NKG2A. Proc Natl Acad Sci USA. (1998) 95:5199-204. doi: 10.1073/pnas.95.9.5199

53. O'Callaghan CA, Tormo J, Willcox BE, Braud VM, Jakobsen BK, Stuart DI, et al. Structural features impose tight peptide binding specificity in the nonclassical MHC molecule HLA-E. Mol Cell (1998) 1:531-41.

54. Bland FA, Lemberg MK, McMichael AJ, Martoglio B, Braud VM. Requirement of the proteasome for the trimming of signal peptidederived epitopes presented by the nonclassical major histocompatibility complex class I molecule HLA-E. J Biol Chem. (2003) 278:33747-52. doi: 10.1074/jbc.M305593200

55. Michaelsson J, Teixeira de Matos C, Achour A, Lanier LL, Kärre K, Söderström K, et al. A signal peptide derived from hsp60 binds HLA-E and interferes with CD94/NKG2A recognition. J Exp Med. (2002) 196:1403-14. doi: $10.1084 / \mathrm{jem} .20020797$

56. Celik AA, Kraemer T, Huyton T, Blasczyk R, Bade-Döding C. The diversity of the HLA-E-restricted peptide repertoire explains the immunological impact of the Arg107Gly mismatch. Immunogenetics (2016) 68:29-41. doi: $10.1007 / \mathrm{s} 00251-015-0880-\mathrm{z}$

57. Kraemer T, Celik AA, Huyton T, Kunze-Schumacher H, Blasczyk R, BadeDöding C. HLA-E : presentation of a broader peptide repertoire impacts the cellular immune response - implications on HSCT outcome. Stem Cells Int. (2015) 2015:346714. doi: 10.1155/2015/346714

58. Lampen MH, Hassan C, Sluijter M, Geluk A, Dijkman K, Tjon JM, et al. Alternative peptide repertoire of HLA-E reveals a binding motif that is strikingly similar to HLA-A2. Mol Immunol. (2013) 53:126-31. doi: 10.1016/j.molimm.2012.07.009

59. Walters LC, Harlos K, Brackenridge S, Rozbeský D, Barrett JR, Jain V, et al. Pathogen-derived HLA-E bound epitopes reveal broad primary anchor pocket tolerability and conformationally malleable peptide binding. Nat Commun. (2018) 9:3137. doi: 10.1038/s41467-018-05459-z

60. Petrie EJ, Clements CS, Lin J, Sullivan LC, Johnson D, Huyton T, et al. CD94-NKG2A recognition of human leukocyte antigen (HLA)-E bound to an HLA class I leader sequence. J Exp Med. (2008) 205:725-35. doi: $10.1084 /$ jem. 20072525

61. Kaiser BK, Pizarro JC, Kerns J, Strong RK. Structural basis for NKG2A/CD94 recognition of HLA-E. Proc Natl Acad Sci USA. (2008) 105:6696-701. doi: 10.1073/pnas.0802736105

62. Morandi F, Pistoia V. Interactions between HLA-G and HLA-E in physiological and pathological conditions. Front Immunol. (2014) 5:394. doi: $10.3389 /$ fimmu.2014.00394

63. Castelli EC, Veiga-Castelli LC, Yaghi L, Moreau P, Donadi EA. Transcriptional and posttranscriptional regulations of the HLA-G gene. $J$ Immunol Res. (2014) 2014:734068. doi: 10.1155/2014/734068

64. Dias FC, Castelli EC, Collares CV, Moreau P, Donadi EA. The role of HLA-G molecule and HLA-G gene polymorphisms in tumors, viral hepatitis, and parasitic diseases. Front Immunol. (2015) 6:9. doi: 10.3389/fimmu.2015.00009

65. Tomasec P, Braud VM, Rickards C, Powell MB, McSharry BP, Gadola S, et al. Surface expression of HLA-E, an inhibitor of natural killer cells, enhanced by human Cytomegalovirus gpUL40. Science (2000) 287:1031-33. doi: 10.1126/science.287.5455.1031

66. Ulbrecht M, Martinozzi S, Grzeschik M, Hengel H, Ellwart JW, Pla M, et al. Cutting edge: the human cytomegalovirus UL40 gene product contains a ligand for HLA-E and prevents NK cell-mediated lysis. J Immunol. (2000) 164:5019-22. doi: 10.4049/jimmunol.164.10.5019

67. Llano M, Gumá M, Ortega M, Angulo A, López-Botet M. Differential effects of US2, US6, and US11 human cytomegalovirus proteins of HLA class Ia and HLA-E expression: Impact on target susceptibility to NK cell subsets. Eur J Immunol. (2003) 33:2744-54. doi: 10.1002/eji.200324182

68. Ulbrecht M, Hofmeister V, Yüksekdag G, Ellwart J, Hengel H, Momburg F, et al. HCMV glycoprotein US6 mediated inhibition of TAP does not affect HLA-E dependent protection of K-562 cells from NK cell lysis. Hum Immunol. (2003) 64:231-7. doi: 10.1016/S0198-8859(02)00788-7 
69. Park B, Spooner E, Houser BL, Strominger JL, Ploegh HL. The HCMV membrane glycoprotein US10 selectively targets HLA-G for degradation. J Exp Med. (2010) 207:2033-41. doi: 10.1084/jem.20091793

70. Heatley SL, Pietra G, Lin J, Widjaja JM, Harpur CM, Lester S, et al. Polymorphism in human cytomegalovirus UL40 impacts on recognition of HLA-E by natural killer cells. J Biol Chem. (2013) 288:8679-90. doi: 10.1074/jbc.M112.409672

71. Prod'homme V, Tomasec P, Cunningham C, Lemberg MK, Stanton RJ, McSharry BP, et al. Human cytomegalovirus UL40 signal peptide regulates cell surface expression of the NK cell ligands HLA-E and gpUL18. J Immunol. (2012) 188:2794-804. doi: 10.4049/jimmunol.1102068

72. Cosman D, Fanger N, Borges L, Kubin M, Chin W, Peterson L, et al. A novel immunoglobulin superfamily receptor for cellular and viral MHC class I molecules. Immunity (1997) 7:273-82. doi: 10.1016/S1074-7613(00)80529-4

73. Prod'homme V, Griffin C, Aicheler RJ, Wang EC, McSharry BP, Rickards $\mathrm{CR}$, et al. The human cytomegalovirus MHC Class I homolog UL18 inhibits LIR-1 ${ }^{+}$but activates LIR-1 ${ }^{-}$NK cells. J Immunol. (2007) 178:4473-81. doi: 10.4049/jimmunol.178.7.4473

74. Björkström NK, Lindgren T, Stoltz M, Fauriat C, Braun M, Evander M, et al. Rapid expansion and long-term persistence of elevated NK cell numbers in humans infected with hantavirus. J Exp Med. (2011) 208:13-21. doi: 10.1084/jem.20100762

75. Rölle A, Pollmann J, Ewen EM, Le VT, Halenius A, Hengel H, et al. IL-12producing monocytes and HLA-E control HCMV-driven NKG2C + NK cell expansion. J Clin Invest. (2014) 124:5305-16. doi: 10.1172/JCI77440

76. Newhook N, Fudge N, Grant M. NK cells generate memory-type responses to human cytomegalovirus-infected fibroblasts. Eur J Immunol. (2017) 47:1032-39. doi: 10.1002/eji.201646819

77. Muntasell A, López-Montañés M, Vera A, Heredia G, Romo N, Peñafiel J, et al. NKG2C zygosity influences CD94/NKG2C receptor function and the NK-cell compartment redistribution in response to human cytomegalovirus. Eur J Immunol. (2013) 43:3268-78. doi: 10.1002/eji.201343773

78. Muntasell A, Pupuleku A, Cisneros E, Vera A, Moraru M, Vilches C, et al. Relationship of NKG2C copy number with the distribution of distinct cytomegalovirus-induced adaptive NK Cell subsets. J Immunol. (2016) 196:3818-27. doi: 10.4049/jimmunol.1502438

79. Noyola DE, Fortuny C, Muntasell A, Noguera-Julian A, Muñoz-Almagro C, Alarcón A, et al. Influence of congenital human cytomegalovirus infection and the NKG2C genotype on NK-cell subset distribution in children. Eur J Immunol. (2012) 42:3256-66. doi: 10.1002/eji.201242752

80. Rölle A, Brodin P. Immune adaptation to environmental influence: the case of NK Cells and HCMV. Trends Immunol. (2016) 37:233-43. doi: 10.1016/j.it.2016.01.005

81. Zheng X, Zhu F, Shi W, Lin A, Yan W. The HLA-G 14 bp insertion/deletion polymorphism is a putative susceptible factor for active human cytomegalovirus infection in children. Tissue Antigens (2009) 74:317-21. doi: 10.1111/j.1399-0039.2009.01312.x

82. Onno M, Pangault C, Le Friec G, Guilloux V, Andre P, Fauchet R. Modulation of HLA-G antigens expression by human Cytomegalovirus: specific induction in activated macrophages harboring human cytomegalovirus infection. $J$ Immunol. (2000) 164:6426-34. doi: 10.4049/jimmunol.164.12.6426

83. Moreau P, Adrian-Cabestre F, Menier C, Guiard V, Gourand L, Dausset J, et al. IL-10 selectively induces HLA-G expression in human trophoblasts and monocytes. Int Immunol. (1999) 11:803-11. doi: 10.1093/intimm/11.5.803

84. Spencer JV, Lockridge KM, Barry PA, Lin G, Tsang M, Penfold ME, et al. Potent immunosuppressive activities of cytomegalovirus-encoded interleukin-10. J Virol. (2002) 76:1285-92. doi: 10.1128/JVI.76.3.1285-1292.2002

85. Avdic S, Mcsharry BP, Steain M, Poole E, Sinclair J, Abendroth A, et al. Human Cytomegalovirus-encoded human interleukin-10 (IL-10) homolog amplifies its immunomodulatory potential by upregulating human IL-10 in monocytes. J Virol. (2016) 90:3819-27. doi: 10.1128/JVI. 03066-15

86. Jun Y, Kim E, Jin M, Sung HC, Han H, Geraghty DE, et al. Human Cytomegalovirus gene products US3 and US6 down-regulate trophoblast class I MHC molecules. J Immunol. (2000) 164:805-11. doi: 10.4049/jimmunol.164.2.805

87. Barel MT, Ressing M, Pizzato N, van Leeuwen D, Le Bouteiller P, Lenfant F, et al. Human cytomegalovirus-encoded US2 differentially affects surface expression of MHC class I locus products and targets membrane-bound, but not soluble HLA-G1 for degradation. J Immunol. (2003) 171:6757-65. doi: 10.4049/jimmunol.171.12.6757

88. Pizzato N, Garmy-Susini B, Le Bouteiller P, Lenfant F. Down-regulation of HLA-G1 cell surface expression in human Cytomegalovirus infected cells. Am J Reprod Immunol. (2003) 50:328-33. doi: 10.1034/j.1600-0897.2003.00087.x

89. Weekes MP, Tomasec P, Huttlin EL, Fielding CA, Nusinow D, Stanton RJ, et al. Quantitative temporal viromics: an approach to investigate host-pathogen interaction. Cell (2014) 157:1460-72. doi: 10.1016/j.cell.2014.04.028

90. Djaoud Z, Riou R, Gavlovsky PJ, Mehlal S, Bressollette C, Gérard N, et al. Cytomegalovirus-infected primary endothelial cells trigger $\mathrm{NKG}_{2} \mathrm{C}^{+}$Natural Killer cells. J Innate Immun. (2016) 8:374-85. doi: 10.1159/000445320

91. Sinclair J, Sissons P. Latency and reactivation of human cytomegalovirus. $J$ Gen Virol. (2006) 87:1763-79. doi: 10.1099/vir.0.81891-0

92. Cichocki F, Cooley S, Davis Z, DeFor TE, Schlums H, Zhang B, et al. $\mathrm{CD}_{56}{ }^{\mathrm{dim}} \mathrm{CD} 57^{+} \mathrm{NKG} 2 \mathrm{C}^{+} \mathrm{NK}$ cell expansion is associated with reduced leukemia relapse after reduced intensity HCT. Leukemia (2016) 30:456-63. doi: 10.1038/leu.2015.260

93. Elmaagacli AH, Steckel NK, Koldehoff M, Hegerfeldt Y, Trenschel R, Ditschkowski $\mathrm{M}$, et al. Early human cytomegalovirus replication after transplantation is associated with a decreased relapse risk: evidence for a putative virus-versus-leukemia effect in acute myeloid leukemia patients. Blood (2011) 118:1402-12. doi: 10.1182/blood-2010-08-304121

94. Green ML, Leisenring WM, Xie H, Walter RB, Mielcarek M, Sandmaier $\mathrm{BM}$, et al. CMV reactivation after allogeneic HCT and relapse risk: evidence for early protection in acute myeloid leukemia. Blood (2013) 122:1316-24. doi: 10.1182/blood-2013-02-487074

95. Ito S, Pophali P, Co W, Koklanaris EK, Superata J, Fahle GA, et al. CMV reactivation is associated with a lower incidence of relapse after allo-SCT for CML. Bone Marrow Transplant. (2013) 48:1313-6. doi: 10.1038/bmt.2013.49

96. Bigley AB, Rezvani K, Shah N, Sekine T, Balneger N, Pistillo M, et al. Latent cytomegalovirus infection enhances anti-tumour cytotoxicity through accumulation of $\mathrm{NKG}_{2} \mathrm{C}^{+} \mathrm{NK}$ cells in healthy humans. Clin Exp Immunol. (2016) 185:239-51. doi: 10.1111/cei.12785

97. Liu LL, Béziat V, Oei VYS, Pfefferle A, Schaffer M, Lehmann S, et al. Ex Vivo Expanded adaptive NK cells effectively kill primary acute lymphoblastic leukemia cells. Cancer Immunol Res. (2017) 5:654-65. doi: 10.1158/2326-6066.CIR-16-0296

98. Torelli GF, Peragine N, Raponi S, Pagliara D, De Propris MS, Vitale $A$, et al. Recognition of adult and pediatric acute lymphoblastic leukemia blasts by natural killer cells. Haematologica (2014) 99:1248-54. doi: 10.3324/haematol.2013.101931

99. Kochan G, Escors D, Breckpot K, Guerrero-Setas D. Role of non-classical MHC class I molecules in cancer immunosuppression. Oncoimmunology (2013) 2:e26491. doi: 10.4161/onci.26491

100. Sarhan D, Cichocki F, Zhang B, Yingst A, Spellman SR, Cooley S, et al. Adaptive NK cells with low TIGIT expression are inherently resistant to myeloid-derived suppressor cells. Cancer Res. (2016) 76:5696-706. doi: 10.1158/0008-5472.CAN-16-0839

101. Sarhan D, Hippen KL, Lemire A, Hying S, Luo X, Lenvik T, et al. Adaptive NK cells resist regulatory T-cell suppression driven by IL37. Cancer Immunol Res. (2018) 6:766-75. doi: 10.1158/2326-6066.CIR-17-0498

102. Davis ZB, Vallera DA, Miller JS, Felices M. Natural killer cells unleashed: checkpoint receptor blockade and BiKE/TriKE utilization in NKmediated anti-tumor immunotherapy. Semin Immunol. (2017) 31:64-75. doi: 10.1016/j.smim.2017.07.011

Conflict of Interest Statement: The authors declare that the research was conducted in the absence of any commercial or financial relationships that could be construed as a potential conflict of interest.

Copyright (C) 2018 Rölle, Jäger and Momburg. This is an open-access article distributed under the terms of the Creative Commons Attribution License (CC BY). The use, distribution or reproduction in other forums is permitted, provided the original author(s) and the copyright owner(s) are credited and that the original publication in this journal is cited, in accordance with accepted academic practice. No use, distribution or reproduction is permitted which does not comply with these terms. 